\title{
Hexaketides from Phytopathogenic Fungus Paraphaeosphaeria recurvifoliae
}

\author{
Changon Seo, Hyuncheol Oh, ${ }^{*}$ Hyang Burm Lee, ${ }^{\dagger}$ Joong Kyun Kim, ${ }^{\dagger}$ In Soo Kong, ${ }^{\ddagger}$ and Soon Cheol Ahn ${ }^{\delta^{*}}$ \\ College of Medical and Life Sciences, Silla Universin, Busan 617-736, Korea. * E-mail: hoh(thsilla.ac.kr \\ ${ }^{+}$Depatment of Applied Bioscience and Biotechnology, Environmental-Friendly Agriculhwe Research Center, \\ College of Agriculture and Life Saiences, Chonnam National Lniversity, Gwangin 500-757, Korea \\ "Department of Biotechnologl and Bioengineering, Ptakyong National University, Busan 608-237, Korea

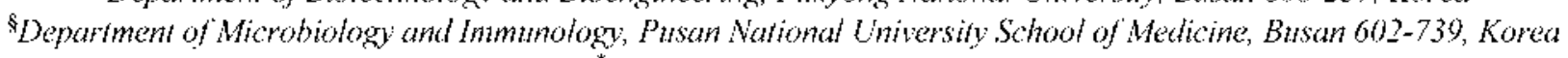 \\ "E-mail: ahnsc(a)ptosan.ac $k r$ \\ Received July 16, 2007
}

Key Words : Phytopathogenic fungi, Fungal metabolites, Structure determination, NMR

Traditionally, natural products serve as valuable agents in a variety of applications such as agrochemicals, antibiotics, inmunosuppressants, antiparasitics, and anticancer agents.' Among all known biologically active natural products, approximately a quarter of them are obtained from fungi. ${ }^{2}$ These fungal metabolites have been isolated after screening of 5000-7000 species, and the number represents only $5 \%$ of the total of 1.5 million fungal species proposed to exist. ${ }^{3}$ Thus, the potential of fungi as sources of further new and useful secondary metabolites is significant.

As part of studies exploring the plant-associated fungi as potential sources of new bioactive secondary metabolites, we investigated a new phytopathogenic fungal species Paraphoeosphacria recurvifoliae isolated from the leaf lesions of pendulous yucca (Kicca recurvifolia) in a garden located in Daejeon, Korea. Chemical investigation of the EtOAc extract of the filtered culture broth obtained from this fungus has led to the isolation of a novel hexaketide $(E)$-5.9dihydroxydodec-6-enoic acid (1), along with closely related known nonenolide-type metabolites herbarumin II (2) and its epimer (3). This report describes the production, isolation, and structure elucidation of these compounds.

The crude extract of fungal culture broth was passed<smiles>[Y2]CCC(O)C/C=C/[C@H](O)CCCC(=O)O</smiles>

1

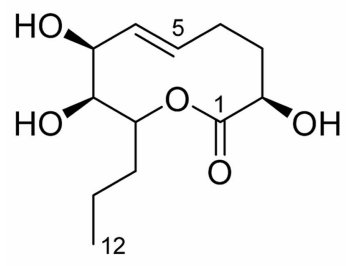

2

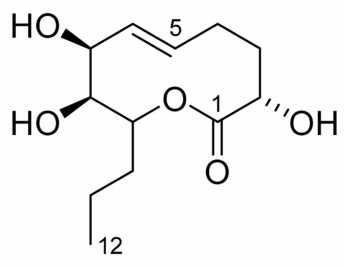

3 through a $\mathrm{C}-18$ flash column and further purified by reversed-phase HPLC to obtain pure compounds 1-3. Compound 1 has the molecular formula $\mathrm{C}_{12} \mathrm{H}_{22} \mathrm{O}_{4}$, as deduced from ${ }^{13} \mathrm{C}$ NMR and HRESIMS data. This formula indicated two degrees of unsaturation. The ${ }^{13} \mathrm{C}$ NMR spectrum for compound 1 contained twelve resolved signals, which were deduced to be one methyl, six methylenes, four methines, and one quaternary carbon from the DEIT-135 spectrum. The 'H NMR spectrum contained a pair of coupled olefinic resonances at $\delta 5.48(J=15.4,6.6,1.5 \mathrm{~Hz})$ and $\delta 5.67(\mathrm{~J}=$ $15.4,7.3 .0 .8 \mathrm{~Hz}$ ), indicating trans geometry of the double bond in 1 . In addition, the presence of a carbonyl group and two oxygenated $\mathrm{sp}^{3}$ methine groups were evident in the $\mathrm{H}$ and ${ }^{13} \mathrm{C}$. NMR spectra, and thus compound 1 must be acyclic compound to account for required unsaturation number. Considering the molecular formula and the NMR data, the three remaining protons must be present as hydroxyl groups, and this consequently indicated the presence of carboxylic acid and two secondary alcohol functionalities in the molecule. An HMQC experiment established the one-bond proton to carbon connectivities, and a COSY experiment established the partially defuned spin systems corresponding to $\mathrm{C} 4-\mathrm{C} 9$ and $\mathrm{C} 11-\mathrm{C} 12$ subunits of structure 1 . Overlapping of the remaining methylene NMR signals precluded further specific assignment, but further connectivities of remaining units were extended using $\mathrm{HMBC}$ correlations. A methylene group $\mathrm{CH}_{2}-10$ was connected to $\mathrm{CH}-9$ and $\mathrm{CH}_{2}-11$ on the basis of $\mathrm{HMBC}$ correlations of $\mathrm{H}_{2}-8$ and $\mathrm{H}_{3}-12$ to $\mathrm{C}-9$. In the HMBC spectrum, cross peak from oxymethine proton at $\delta$ $4.00(\mathrm{H}-5)$ to the methylene carbon at $\delta 22.7(\mathrm{C}-3)$ was observed. Accordingly, $\mathrm{CH}_{2}-3$ was connected to $\mathrm{CH}_{2}-4$. The remaining methylene protons $\left(\mathrm{CH}_{2}-2\right)$ correlated to $\mathrm{C}-1$ and $\mathrm{C}-4$ in the HMBC spectrum, and this observation, along with $\mathrm{HMBC}$ correlation of $\mathrm{H}_{2}-3$ with $\mathrm{C}-1$, established the location of $\mathrm{C}-1$ and $\mathrm{C}-2$. Finally, the remaining three hydroxyl groups were assigned to two secondary alcohols $(C-5$ and $C-9)$ and carboxylic acid moiety $(\mathrm{C}-1)$ to complete the assignment of the structure 1 . Thus, the gross structure of 1 was assigned as 
(E)-5,9-dihydroxydodec-6-enoic acid.

The signal systems of ${ }^{1} \mathrm{H}$ and ${ }^{13} \mathrm{C}$ NMR data for compound 2 resembled those observed for compound $\mathbf{1}$, suggesting structural similarity between $\mathbf{1}$ and $\mathbf{2}$. The signals for two aliphatic methylene units in 1 were replaced by the signals for two new oxygenated methine units in the spectra of 2. Another evident difference was that one of the oxymethine signals $(\delta 5.14)$ in 1 was shifted downfield by $1.57 \mathrm{ppm}$ relative to that of compound 1 , and this suggested that the oxygenated methine was involved in an ester linkage to carbonyl carbon resonated at $\delta 175.5$. The molecular formula for 2 was established as $\mathrm{C}_{12} \mathrm{H}_{20} \mathrm{O}$; on the basis of LRESIMS and NMR data. Ultimately, taking into account these data, the structure of $\mathbf{2}$ was identified as herbarumin II by comparison of the NMR data to literature values. ${ }^{\text {ta }}$ Herbarumin II (2) has been isolated from a culture broth of the fungus Phoma herbarnm with phytotoxic effect possibly by inhibiting calmodulin-dependent cyclic nucleotide phosphodiesterase (cAMP). ${ }^{+}$

The NMR data for compound 3 were very similar to those of 2 except for the difference in chemical shift values for $\mathrm{H}$ 2 ( $\delta 3.84$ vs. 4.24, Table 2). LRESIMS and NMR data revealed that compound 3 has the same molecular formula as that of $\mathbf{2}$. These data suggested a diastereomeric relationship between 2 and 3 . Once the stereochemistry of herbarumin II (2) was readily assigned by comparison of $[\alpha] \mathrm{D}$ values, chemical shifts, and $J$ values to literature values, ${ }^{\text {ta }}$ the stereochemistry of 3 was proposed by comparison of the chemical shifts and $J$ values with those of 2. Especially, the $J_{\mathrm{H} 2-\mathrm{Hs}}$ couplings in compound $2(10.6 \mathrm{~Hz}$ and $3.3 \mathrm{~Hz})$ and 3 $(5.8 \mathrm{~Hz}$ and $1.8 \mathrm{~Hz})$ were markedly different. Considering established conformation of nonenolide, this observation suggested pseudoaxial disposition of the hydroxyl group at $\mathrm{C}-2$ in structure 3 in contrast to pseudoequatorial disposition in structure 2. Thus the structure of compound 3 was assigned as $\mathrm{C}-2$ epimer of $\mathbf{2}$. The $\mathrm{C}-2$ epimer of herbarumin II (3) has been prepared in the course of the synthesis of pinolidoxin, which is a phytotoxic nonenolide with pseudoaxially oriented $2-O$-hexadienoyl group. ${ }^{4 a}$ Although direct comparison of the NMR data with those for the synthetic material was impossible due to the absence of spectroscopic data for the synthetic material, comparison of the coupling constants at the stereogenic centers at $\mathrm{C}-2, \mathrm{C}-7, \mathrm{C}-8$, and $\mathrm{C}-9$ in 3 with those of pinolidoxin was fully consistent with the proposed stereochemistry as shown in 3. To our best knowledge, this is the first case to report the isolation of $\mathrm{C}-2$ epimer of herbarumin II from natural sources.

All three compounds were tested for inhibitory activity against murine tyrosinase partially purified from melanoma B-16 cells at a concentration of $1.3 \mathrm{mg} / \mathrm{mL}$, and compounds 1-3 showed weak activity displaying inhibitory percentage of $30 \%, 17 \%$, and $12 \%$, respectively. Kojic acid was used as a positive control, and showed inhibitory percentage of $85 \%$ at the same concentration.

\section{Experimental Section}

General Experimental Procedures. Optical rotations were recorded on a Perkin Elmer 341 digital polarimeter. ESIMS data were obtained at the Korean Basic Science Institute, Daejeon, Korea. NMR spectra (1D and 2D) were recorded in $\mathrm{CD}_{3} \mathrm{OD}$ using a JEOL JNM ECP-400 spectrometer $\left(400 \mathrm{MHz}\right.$ for ${ }^{1} \mathrm{H}$ and $100 \mathrm{MHz}$ for ${ }^{13} \mathrm{C}$ ), and chemical shifts were referenced relative to the corresponding residual solvents signals ( $\mathrm{CD}_{3} \mathrm{OD}: \delta 3.30 / 49.0$ ). $\mathrm{HMQC}$ and $\mathrm{HMBC}$ experiments were optimized for ${ }^{1} J_{\mathrm{CII}}=140 \mathrm{~Hz}$ and ${ }^{\mathrm{n}} J_{\mathrm{CII}}=8$ $\mathrm{Hz}$, respectively. Solvents for extractions and open column chromatography were reagent grade and used without further purification. Solvents used for HPLC were analytical grade. Flash column chromatography was carried out using

Table 1. 1D and 2D NMR data for 1 in $\mathrm{CD}_{3} \mathrm{OD}$

\begin{tabular}{|c|c|c|c|c|}
\hline no & $\delta_{\mathrm{C}}(\mathrm{mult})^{a}$ & $\delta_{\mathrm{II}}(\mathrm{int}, \mathrm{mult}, J \text { in } \mathrm{Hz})^{h}$ & $\operatorname{COSY}$ & $\mathrm{HMBC}(\mathrm{H} \rightarrow \mathrm{C})$ \\
\hline 1 & $179.1(s)$ & - & - & - \\
\hline 2 & $36.1(t)$ & $2.25(2 \mathrm{H}, \mathrm{t}, 7.3)$ & - & $\mathrm{C}-1, \mathrm{C}-3, \mathrm{C}-4$ \\
\hline 3 & $22.7(\mathrm{t})$ & $\begin{array}{l}1.65(1 \mathrm{H}, \mathrm{m}) \\
1.57(1 \mathrm{H}, \mathrm{m})\end{array}$ & - & $C-1, C-4$ \\
\hline 4 & $37.9(t)$ & $\begin{array}{l}1.51(1 \mathrm{H}, \mathrm{m}) \\
1.47(1 \mathrm{H}, \mathrm{m})\end{array}$ & - & $\mathrm{C}-5, \mathrm{C}-6$ \\
\hline $5^{*}$ & 73.3 (d) & $4.00(1 \mathrm{H}, \mathrm{dd}, 13.2,6.6)$ & $\mathrm{H}-4, \mathrm{H}-6$ & $C-3, C-4, C-6, C-7$ \\
\hline 6 & 136.6 (d) & $5.48(1 \mathrm{H}, \mathrm{ddt}, 15.4,6.6,1.5)$ & $\mathrm{H}-5, \mathrm{H}-7$ & $\mathrm{C}-5, \mathrm{C}-7, \mathrm{C}-8$ \\
\hline 7 & 128.8 (d) & $5.67(1 \mathrm{H}, \mathrm{dtd}, 15.4,7.3,0.8)$ & $\mathrm{H}-6, \mathrm{H}-8$ & $C-6, C-8, C-13$ \\
\hline 8 & $41.3(t)$ & $2.18(2 \mathrm{H}, \mathrm{dd}, 14.3,7.3)$ & $\mathrm{H}-7, \mathrm{H}-9$ & $C-6, C-7, C-9, C-10$ \\
\hline 9 & 72.0 (d) & $3.58(1 \mathrm{H}, \mathrm{m})$ & $\mathrm{H}-8$ & $C-11$ \\
\hline 10 & $40.0(t)$ & $\begin{array}{l}1.44(1 \mathrm{H}, \mathrm{m}) \\
1.36(1 \mathrm{H}, \mathrm{m})\end{array}$ & - & - \\
\hline 11 & $19.9(t)$ & $\begin{array}{l}1.47(1 \mathrm{H}, \mathrm{m}) \\
1.34(1 \mathrm{H}, \mathrm{m})\end{array}$ & - & $C-10$ \\
\hline 12 & $14.4(\mathfrak{q})$ & $0.92(1 \mathrm{H}, \mathrm{t}, 6.6)$ & $\mathrm{H}-11$ & $C-10, C-11$ \\
\hline
\end{tabular}

"Recorded at $100 \mathrm{MIz}$ Carbon multiplicities were determined by DEPT experiments. "Recorded at $400 \mathrm{MIz}$ "Correlations were ambiguous due to signal overlapping. 
Table 2. ${ }^{1} \mathrm{H}$ and ${ }^{13} \mathrm{C}$ NMR data for 2 and 3 in $\mathrm{CD}_{3} \mathrm{OD}$

\begin{tabular}{|c|c|c|c|c|}
\hline \multirow{2}{*}{ no } & \multicolumn{2}{|r|}{2} & \multicolumn{2}{|r|}{3} \\
\hline & $\delta_{c}(\text { mult })^{a}$ & $\delta_{\mathrm{I}}(\mathrm{int}, \mathrm{mult}, J \text { in } \mathrm{Hz})^{h}$ & $\delta_{\mathrm{C}}(\text { mult })^{\mu}$ & $\delta_{\mathrm{II}}(\text { int, mult, } J \text { in } \mathrm{Hz})^{b}$ \\
\hline 1 & $176.9(s)$ & - & $176.5(s)$ & - \\
\hline 2 & $73.6(t)$ & $3.84(1 \mathrm{H}, \mathrm{dd}, 10.6,3.3)$ & $70.7(t)$ & $4.24(1 \mathrm{H}, \mathrm{dd}, 5.8,1.8)$ \\
\hline 3 & $34.0(t)$ & $\begin{array}{l}1.89(1 \mathrm{H}, \mathrm{m}) \\
1.79(1 \mathrm{H}, \mathrm{m})\end{array}$ & $33.2(\mathrm{t})$ & $\begin{array}{l}1.95(1 \mathrm{H}, \mathrm{m}) \\
1.85(1 \mathrm{H}, \mathrm{m})\end{array}$ \\
\hline 4 & $29.7(t)$ & $\begin{array}{l}2.29(1 \mathrm{H}, \mathrm{dm}, 13.6) \\
2.09(1 \mathrm{H}, \mathrm{m})\end{array}$ & $27.7(t)$ & $\begin{array}{l}2.42(1 \mathrm{H}, \mathrm{dm}, 13.6) \\
2.05(1 \mathrm{H}, \mathrm{m})\end{array}$ \\
\hline 5 & $123.5(d)$ & $5.49(1 \mathrm{H}$, dddd, $15.8,9.2,3.7,1.5)$ & $123.6(d)$ & $5.48(1 \mathrm{H}, \mathrm{dddd}, 15.4,11.4,4.0 .2 .2)$ \\
\hline 6 & $134.1(d)$ & $5.56(1 \mathrm{H}$, br dd, $15.8,2.2)$ & $135.0(d)$ & $5.71(1 \mathrm{H}$, br $d, 15.4)$ \\
\hline 7 & 73.9 (d) & $4.34(1 \mathrm{H}$, quint, 1.8$)$ & 74.2 (d) & $4.39(1 \mathrm{H}$, quint, 2.2$)$ \\
\hline 8 & 74.1 (d) & $3.51(1 \mathrm{H}, \mathrm{dd}, 9.9,2.2)$ & $74.1(d)$ & $3.58(1 \mathrm{H}, \mathrm{dd}, 9.5,2.6)$ \\
\hline 9 & 71.9 (d) & $5.15(1 \mathrm{H}, \mathrm{td}, 9.2,2.6)$ & 72.5 (d) & $5.22(1 \mathrm{H}, \mathrm{td}, 9.2 .2 .6)$ \\
\hline 10 & $35.2(\mathrm{t})$ & $\begin{array}{l}1.82(1 \mathrm{H}, \mathrm{m}) \\
1.52(1 \mathrm{H}, \mathrm{m})\end{array}$ & $35.1(t)$ & $\begin{array}{l}1.85(1 \mathrm{H}, \mathrm{m}) \\
1.55(1 \mathrm{H}, \mathrm{m})\end{array}$ \\
\hline 11 & $18.6(t)$ & $\begin{array}{l}1.41(1 \mathrm{H}, \mathrm{m}) \\
1.31(1 \mathrm{H}, \mathrm{m})\end{array}$ & $19.0(t)$ & $\begin{array}{l}1.37(1 \mathrm{H}, \mathrm{m}) \\
1.28(1 \mathrm{H}, \mathrm{m})\end{array}$ \\
\hline 12 & $14.4(q)$ & $0.92(1 \mathrm{H}, \mathrm{t}, 7.3)$ & $14.5(q)$ & $0.91(1 \mathrm{H}, \mathrm{t}, 7.3)$ \\
\hline
\end{tabular}

"Recorded at $100 \mathrm{MI}$. Carbon multiplicities were determined by DEPT experiments. "Recorded at $400 \mathrm{MII}$.

Aldrich octadecyl-functionalized silica gel $\left(\mathrm{C}_{18}\right)$. HPLC separations were performed on a Shiseido Capcell Pak C18 column $(10 \times 250 \mathrm{~mm} ; 5-\mu \mathrm{m}$ particle size $)$ with a flow rate of $2 \mathrm{~mL} / \mathrm{min}$. Compounds were detected by UV absorption at $210 \mathrm{~nm}$.

Characterization and Fermentation of the Organism. A fungal strain, EML-PLO01 was isolated from the leaf spots and necrosis lesion of pendulous yucca (Yucca rectirvifolia) collected in a house garden of Korea. The strain was then plated onto a selective medium, yeast-malt extract agar (YMA; yeast-malt extract $3 \mathrm{~g} / \mathrm{L}$, tryptone $5 \mathrm{~g} / \mathrm{L}$, glucose $10 \mathrm{~g} / \mathrm{L}$, agar $15 \mathrm{~g} / \mathrm{L}, \mathrm{pH} 3.7$ ) and incubated at $25^{\circ} \mathrm{C}$. The fungal isolate has been recently identified as a new species of Paraphaeosphaeria recurvifoliae based on the morphology of pycnidia and pycnidiospores, and ITS rDNA sequence data. ${ }^{6}$ Subcultures of the fungus were deposited at Environmental Microbiology Lab, Chon am Natl' University. Five flasks, each containing $200 \mathrm{~mL}$ of potato dextrose broth that had been sterilized at $120^{\circ} \mathrm{C}$ for $15 \mathrm{~min}$ and then cooled to room temperature, were individually inoculated with $1-\mathrm{cm}^{2}$ agar plugs taken from stock cultures of the fungus maintained on potato dextrose agar. Flask cultures were inoculated at $25-28^{\circ} \mathrm{C}$ and aerated by agitation on an orbital shaker at 150 ppm for 14 days.

Isolation and Characterization of Compounds 1-3. Solvent partitioning of the filtered fermentation broth with EtOAc $(5 \times 200 \mathrm{~mL})$ provided an organic phase, which was then concentrated using a rotary evaporator to yield $1.1 \mathrm{~g}$ of crude extract. The crude extract was subjected to $\mathrm{C}_{18}$ functionalized silica gel flash column chromatography $(5 \times$ $15 \mathrm{~cm}$ ), eluting with a stepwise gradient of $20 \%, 40 \%, 60 \%$, $80 \%$, and $100 \%(\mathrm{v} / \mathrm{v}) \mathrm{MeOH}$ in $\mathrm{H}_{2} \mathrm{O}(300 \mathrm{~mL}$ each, 5 fractions). The fraction eluted at $60 \% \mathrm{MeOH}(232 \mathrm{mg})$ was reapplied to silica gel flash column chromatography, eluting with a stepwise gradient consisting of $\mathrm{CH}_{2} \mathrm{Cl}_{2}$ in $\mathrm{MeOH}(5 \%$
$600 \mathrm{~mL}, 10 \% 600 \mathrm{~mL}$, and $100 \% \mathrm{MeOH} 200 \mathrm{~mL}$ ). Altogether 58 fractions were collected ( $25 \mathrm{~mL}$ each), and pooled based on TLC behavior to afford 9 major fractions. Fraction $(57.1 \mathrm{mg}$ ) eluted with $100 \% \mathrm{MeOH}$ (between 1325 $\mathrm{mL}$ and $1400 \mathrm{~mL}$ ) was then fractionated through a Sephadex LH-20 column $(2.5 \times 30 \mathrm{~cm})$ using a $20 \% \mathrm{MeOH}$ in acetone, collecting a total of 20 fractions $(20 \mathrm{~mL}$ each). Fractions were pooled by TLC profile to afford compound $1(10.3 \mathrm{mg}$, fractions 6 to 11$)$. Fraction $(65.5 \mathrm{mg})$ eluted with $10 \%$ $\mathrm{CH}_{2} \mathrm{Cl}_{2}$ in $\mathrm{MeOH}$ (between $1325 \mathrm{~mL}$ to $1400 \mathrm{~mL}$ ) from silica gel column was processed by semi-preparative reversed-phase HPLC using a gradient from 10 to $30 \% \mathrm{CH}_{3} \mathrm{CN}$ in $\mathrm{H}_{2} \mathrm{O}\left(0.1 \%\right.$ formic acid) over $50 \mathrm{~min}$ to yield $2\left(13.5 \mathrm{mg} ; \mathrm{V}_{\mathrm{R}}\right.$ $=68-72 \mathrm{~mL})$ and $3\left(11.0 \mathrm{mg} ; \mathrm{V}_{\mathrm{R}}=52-56 \mathrm{~mL}\right)$.

(E)-5,9-Dihydroxydodec-6-enoic Acid (1): white oil; $[\alpha]_{\mathrm{D}}^{25}+3(c 0.5, \mathrm{MeOH}) ;{ }^{1} \mathrm{H},{ }^{13} \mathrm{C}$, and $2 \mathrm{D} N \mathrm{NR}$ data, Table 1 ; HRESIMS $m / z 253.1405(\mathrm{M}+\mathrm{Na})^{+}$(calc. for $\mathrm{C}_{12} \mathrm{H}_{22} \mathrm{O}_{4} \mathrm{Na}$, 253.1416 ). Copies of the original spectra are obtainable from the author of correspondence.

Herbarumin II (2): white solid; $[\alpha]_{\mathrm{D}}^{25}+27$ (c 0.45 , $\mathrm{MeOH}) ;{ }^{\prime} \mathrm{H},{ }^{13} \mathrm{C}$, and $2 \mathrm{D}$ NMR data, Table 2; LRESIMS $m / z$ $243(\mathrm{M}-\mathrm{H})^{-}$.

C-2 Epimer of Herbarumin $\Pi$ (3): yellow gum; $[\alpha]_{D}^{25}+$ 15 (c $0.66, \mathrm{MeOH}) ;{ }^{1} \mathrm{H},{ }^{13} \mathrm{C}$, and $2 \mathrm{D}$ NMR data, Table 2; LRESIMS $m / z 243(\mathrm{M}-\mathrm{H})^{-}$.

Acknowledgments. This work was supported by a grant (M2007-06) from Marine Bioprocess Research Center of the Marine Bio 21 Center funded by the Ministry of Maritime Affairs \& Fisheries, Republic of Korea. Mass spectral data were kindly provided by the Korea Basic Science Institute.

\section{References}

I. Newman, D. J.; Cragg, G. M. J. Nat. Prod. 2007, 70, 461-477. 
2. (a) Henkel, T; Brunne, R. M.; Muller, H.; Reichel, F. Angew. Chem. Chent. Int. Ed. 1999, 38, 643-647. (b) Pearce, C. Adk. Appl. Microbiol. 1997, 44, 1-80.

3. (a) Dreyfuss, M. H.; Chapela, I. H. Potential of Fungi in the Discovery of Novel Low-Molecular Weight Pharmacenticals in The Discovery of Natural Products with Therapentic Potential; Gullo, V. P., Ed.; Butterworth-Heinemann: Boston. 1994; pp 4980. (b) Gloer, J. B. Applications of Fingat Ecology in the Search for New Bioactive Natural Products in The Mycola $\mathrm{W}$ Environmental and Microbial Relationships; Wicklow, D. T.; Soderstrom, B., Eds.; Springer-Verlag: Berlin, 1997; pp 249-268. (c) Hawksworth, D. L. Mycol. Res. 1991, 95,64l-655. (d) Hawksworth, D. L.; Kirsop. B. E. Living Resources for Biotecholog; Filimentous Fungi; Cambridge University Press: Cambridge, MA,
1988.

4. (a) Furstner, A.; Radkowski, K.; Wirtz, C.; Goddard, R; Lehmann, C. W.; Mynott, R. J. An. Chem. Soc. 2002, 124, 7061-7069. (b) Rivero-Cruz, J. F.; Garcia-aguirre, Gi; Cerda-Garcia-Rojas, C. M.; Mata, R. Tetrahedron 2000, 56, 5337-5344. (c) Rivero-Cruz, J. F.; Macias, M.; Cerda-Garcia-Rojas, C. M.; Mata, R. J. Nat. Prod. $2003,66.511-514$.

5. For the preparation of murine tyrosinase and measurement of tyrosinase activity, see; (a) Kim, Y. M.; Yun, J.; Lee, C.-K.; Lee, H.; Min, K. R. J. Biol. Chem, 2002, 277, 16340-16344. (b) Jeon, S.-H.; Kim, K.-H.; Koh, J.-U.; Kong, K.-H. Bull. Korean Chem. Soc. 2005, 26, $1135-1137$.

6. Lee, H. B.; Kim, K. M.; Jung, H. S. Fungal Diversity 2005, 20 , $71-81$. 